\title{
Performance Analyses of a Multiple Horizontal Tubes for Steam Condensation
}

\author{
Dharmendra waiker ${ }^{1}$ Ajay Singh ${ }^{2}$ Sunil Patidar $^{3}$ Soniya Parihar $^{4}$ \\ ${ }^{1}$ Asst. Prof. ${ }^{2}$ Associate Professor ${ }^{3}$ Asst.Prof. ${ }^{4}$ Asst. Prof \\ Department of Mechanical Engineering ,RITS, Bhopal (M.P.) India
}

\begin{abstract}
This Investigation is carried out to find out the effect of Tube Inclination of Steam Flowing Tube on Steam Condensation. The Steam Condensation Problem on a Vertical Tier of Horizontal Tubes is investigated by both Analytical and Experimental Methods in this Study. A Analytical Method is used to perform the Analysis of Laminar Film Condensation on the Horizontal Tubes. This is capable to calculate Condensate film thickness velocity distribution, and the Heat Transfer Coefficient within the Condensate. An experimental setup was also manufactured to observe the Condensation Phenomenon on Horizontal Tubes. As we know that generally the Saturated Steam produced by the Boiler at 1.0 MPa has the two heat Components:
\end{abstract}

Latent Heat $=70 \%$ Sensible Heat $=30 \%$ So in this Investigation we want to Transfer the Latent Heat from Steam \& get a Condensate which already has two Components:

CONDENSATE $=$ WATER + SENSIBLE HEAT

Keywords:Condensation, Laminar flow, Horizontal Tube, Inclination, Film Thickness

\section{Introduction}

to liquid state. When the temperature of a vapor goes below its saturation temperature, condensation occurs. A certain amount of sub cooling is required for condensation. Hence, energy in the latent heat form must be removed from the condensation area during the phase change process. A pressure decrease happens in the region of condensation results a mass diffusion toward this region.

Condensation can be classified as bulk condensation and surface condensation.

Vapor condenses as droplets suspended in a gas phase in the bulk condensation. When condensation takes place randomly within the bulk of the vapor, it is called homogeneous condensation. If condensation occurs on foreign particles exist in the vapor, this type of bulk condensation is defined as heterogeneous condensation. Fog is a typical example of this type of condensation.

Surface condensation occurs when the vapor contacts with a surface whose temperature is below the saturation temperature of the vapor. Surface condensation has a wide application area in the industry. It is classified as film wise and drop wise condensation.

Film condensation occurs when the liquid wets the surface and the condenser surface is blanketed by a condensate film. This film represents a thermal resistance to heat transfer and a temperature gradient exists in the film. The analytical investigation of film condensation was first performed by Nusselt in 1916. He neglected the effects of vapor drag and fluid accelerations. He assumed that flow is laminar throughout the film. It is further assumed that a linear temperature distribution and a parabolic velocity profile exist between walls and vapor conditions. Despite the complexities associated with film condensation, Nusselt achieved to get reasonable and realistic results by making his assumptions.

Drop wise condensation occurs on a surface which is coated with a substance that inhibits wetting. Heat transfer rates in drop wise condensation May bête times higher than in film condensation. Since very high heat transfer rates can be obtained in drop wise condensation, it is always desired in applications. It is possible to reduce the heat transfer area half or less in a condenser system by using drop wise condensation.

\section{Literature Survey}

Review of the previous studies about condensation will be presented in this section. The research is mainly based on two subjects; laminar film condensation and the condensation of vapor on a horizontal cylinder.

The analysis of laminar film condensation was first performed by Nusselt [1]. He proposed a simple model of the physical phenomenon which is capable to calculate film thickness and heat transfer coefficient for different geometrical configurations. He neglected the effects of both energy convection and fluid accelerations within the condensate layer and the shear stress at the liquid-vapor interface. Nusselt assumed that flow throughout the film is laminar and only gravity forces are acting on the condensate layer. A simple balance between the gravity and the shear forces was created in the analysis. The gas is assumed to be a pure vapor rat a uniform temperature equal to $\mathrm{T}_{\text {sat }}$. Heat transfer from vapor to liquid is only carried out by condensation and 
constant fluid properties are assumed for the liquid film. It is further assumed that a linear temperature distribution exists across the condensate layer.

Dukler [2] developed new equations for velocity and temperature distribution in thin vertical films. Since these equations are too complex for analytical solution, he used numerical solution. The equations he derived utilize the expression proposed by deissler for the eddy viscosity and eddy thermal conductivity. He calculated average condensing heat transfer coefficients and liquid film thickness from the velocity and temperature distributions. He showed that results are in good agreement with the classical Nusselt's theory at low Reynolds numbers and in the turbulent region, he obtained agreement with the empirical relationships of colburn for fully developed turbulent flow in the absence of interfacial shear.

Abdullah et al. [3] performed an experimental setup so as to investigate condensation of steam and r113 on a bank of horizontal tubes and the influence of a non condensing gas. Data were in good agreement with single-tube theory at the top of the bank but were found very lower in the vapor side heat transfer coefficient. Air, which is a non condensing gas, causes a sharp decrease in the heat transfer coefficient when exists in the vapor.

Kumar et al. [4] performed an experimental investigation to find out the behavior of the condensing side heat transfer coefficient $h_{o}$, over a plain tube; a circular integral-fin tube (cift) and a spine integral-fin tube (sift). It was concluded that cift and sift have an enhancement on the condensing side heat transfer coefficient by a factor of 2.5 and 3.2, respectively. Besides, sift offers about 30 percent more enhancements in $\mathrm{h}_{\mathrm{o}}$ with respect to cift.

Kutateladzeand gogonin [5] also investigated the influence of condensate flow rate on heat transfer in film condensation. Condensation of quiescent vapor on the banks of horizontal smooth tubes of different diameters was analyzed. It was pointed out that vapor condensation on super cooled drops and discrete liquid streamlets contributes to heat transfer at re > 50 and both Reynolds number and the diameter of the cylinder have a considerable effect on the starting length of the thermal boundary layer.

Chen [6] investigated laminar film condensation around a single horizontal tube and a vertical bank of horizontal tubes. He considered the inertia effects and assumed the vapor is stationary for the single tube case. Chen found that the inertia forces have a larger effect on the heat transfer of round tubes than flat plates. For the multiple tube case, he neglected the inertia effects and the unpredictable effects of splashing and ripples. He also stated that boundary condition at the top of the lower tubes is largely influenced by the momentum gain and the condensation between tubes. Comparison of heat transfer coefficients with experimental data had been accomplished and the theoretical results were expressed as approximate formulas for both cases.

\section{Analytical \& Experimental Procedure}

3.1 ANALYTICAL MODEL- The Condensation of Steam over a vertical tier of horizontal tube is investigated by both analytical and experimental methods during this study. An analytical model has been developed with the help of the lecture notes of Arpac1. Two equations, which are obtained by applying the principles of conservationof mass and conservation of momentum on the condensate layer, are transformed into the finite difference forms. Thus, the problem is turned to a state that can be solved by the computer. A computer program, which uses the Newton-Raphsonmethod, has been implemented in order to analyses the problem. The program gives the film thickness and the velocity distribution of the condensate for each condensation tubes.

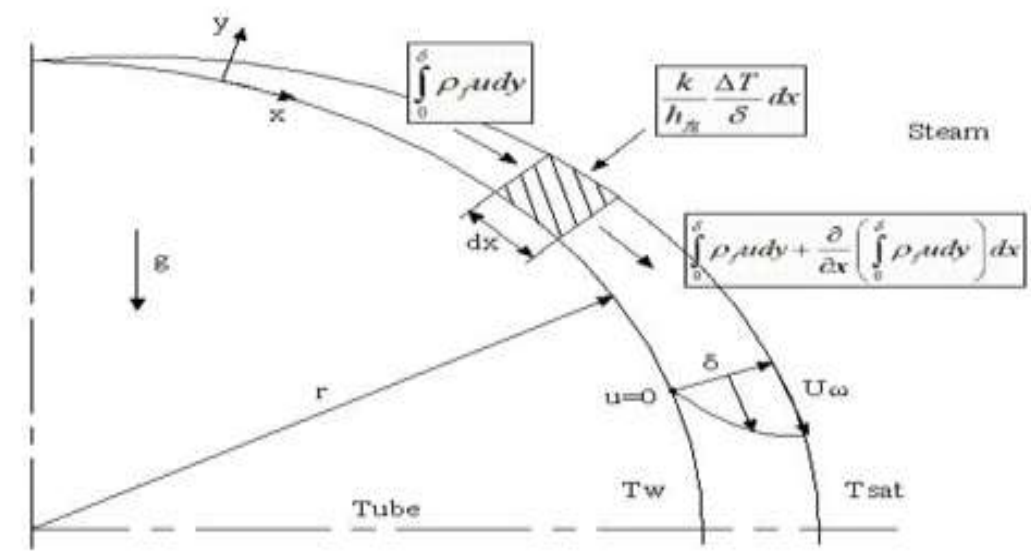

Figure 3.1 Physical Models and Coordinate System 
3.2 EXPERIMENTAL PROCEDURE - The purposes of the experiments are to find out the amount of heat transfer rate from steam to cold water and the heat transfer coefficient of the condensate layer. As the steam condenses on the horizontal tubes, the energy in the latent heat form is released from the steam to cold water. Since this energy given by the steam is equal to the energy taken by the cold water, heat transfer coefficient can be obtained from the equality below:

$$
\begin{aligned}
& \mathrm{Q}=\mathrm{m} \mathrm{c}_{\mathrm{p}}\left(\mathrm{T}_{\text {out }}-\mathrm{T}_{\text {in }}\right) \\
& \mathrm{Q}=\mathrm{h}_{\text {cond }} \mathrm{A}\left(\mathrm{T}_{\text {sat }}-\mathrm{T}_{\mathrm{w}}\right)
\end{aligned}
$$

Experiments are performed in three different stages:

1. Condensation phenomenon on multiple horizontal tubes has been investigated at different inclination angles of the setup. The reason of inclining the setup is to see how condensation is affected at the lower tubes when condensate does not fall onto the Centre line of the tubes. Experiments of this stage have been achieved for $0^{\circ}, 3^{\circ}, 6^{\circ}, 10^{\circ}$ and $15^{\circ}$ of inclination angles. The schematic drawings of condensate behavior at different angles are given in appendix a. The inclination angle, which ensures that the condensate spilling from the upper tube does not fall onto the lower tubes, is determined as $15^{\circ}$ in the computer environment. The results of the experiments made with this angle show that the heat transfer rates of three condensation tubes are very close to each other. Therefore, the angle assumed at the beginning of the experiments is verified. The other angles are determined by dividing the angle interval evenly considering the situation of the condensate's fall.

2. Additional flow delimiters are placed into the setup to narrow the flow area of the steam. The idea behind this stage is to improve the condensation phenomenon as the steam is forced to flow in narrower section. Thus, the sweep effect of the steam on the condensate layer has been increased, resulting the film thickness of the condensate decreases. A schematic representation of this stage is depicted in figure 3.2.

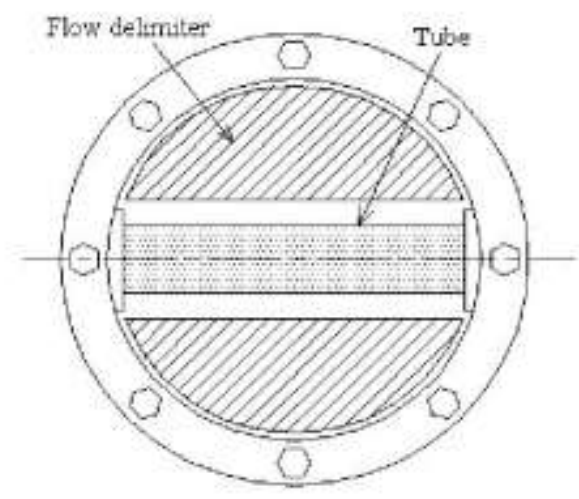

Figure 3.2 top view of the test section with flow delimiter on a

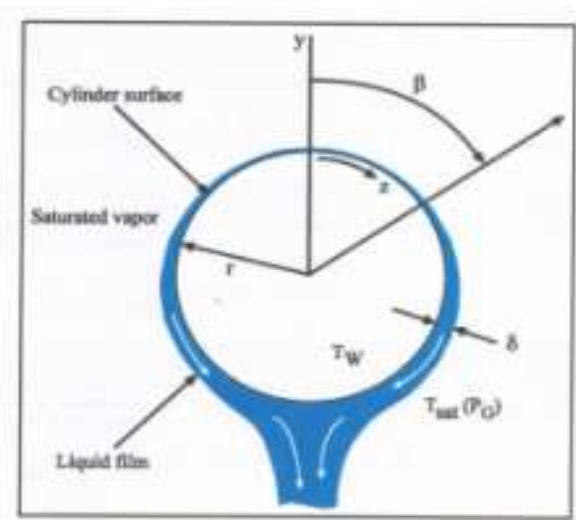

Figure 3.3 Condensation model for film condensation horizontal tube

3. The condensation tube in the middle and the flow delimiters are removed from the setup. Hence, the distance between two horizontal tubes is increased resulting splashing and attenuation effects of the condensate are increased. Experiments start with turning on the heater of the boiler. The heater of the cold water tank may be initiated depending on the cooling water temperature desired by the experiment. As soon as cooling water temperature reaches to desired value, the heater is plugged out. Meanwhile, boiler is about to begins end in gathers team to the setup. A certain period of time is waited for the test section to be purged and free of air. After the test section is filled up with steam, the valve of the cooling water tank is opened and the water flows down to the horizontal condensation tubes. Cooling water flow rate is determined by measuring the time for filling out pre defined vessel after the system has stabilized, data recording is commenced. The varying factor of the experiments is the cooling water temperature value. Surface temperature of the condensation tubes changes by adjusting the cold water temperature. Variac is used to control the steam flow rate in some experiments. The data tables obtained from the experiments are given in appendix..

\section{Analytical \& Experimental Result}

\subsection{Analytical Results}

It is based on the theoretical model which is developed tocalculate film thickness and velocity distribution in the condensate film. Thermo physical properties and geometric dimensions are defined at the beginning of the program. By changing the thermo physical properties, it is possible to examine Condensation phenomenon on a vertical tier of three horizontal tubes for various working fluids. The fundamental geometric parameter is the diameter of the tubes. The effect of the tube diameter on the film 
thickness, velocity of the condensate, heat fluxes and heat transfer coefficient will be discussed. The analytical results which are obtained at different tube diameters will be used to study the effect of tube diameter on condensation heat transfer. Another parameter that significantly affects condensation rate is the difference between the saturation temperature of steam and the wall temperature of the tube. The results which are obtained for different $\Delta \mathrm{T}$ values will be used to study the effect of steam to wall temperature difference on condensation heat transfer.

\subsection{Experimental Results}

The results of the experiments are obtained for three different stages. Heat transfer rate is obtained from the measured mass flow rate, the inlet and outlet temperatures of the cooling water. Condensation heat transfer coefficient is calculated by the convection heat transfer formula:

$$
\begin{aligned}
& \mathrm{Q}=\mathrm{m} c_{\mathrm{p}}\left(\mathrm{T}_{\text {out }}-\mathrm{T}_{\text {in }}\right) \\
& \mathbf{h}_{\text {cond }}=\frac{\mathbf{Q}}{2 \pi \mathrm{RL}\left(\mathrm{T}_{\text {sat }}-\mathrm{T}_{\mathbf{w}}\right)}
\end{aligned}
$$

4.2.1 Results of the Experiments Made at Different Angular Orientation of Tube Columns

\section{Degree}

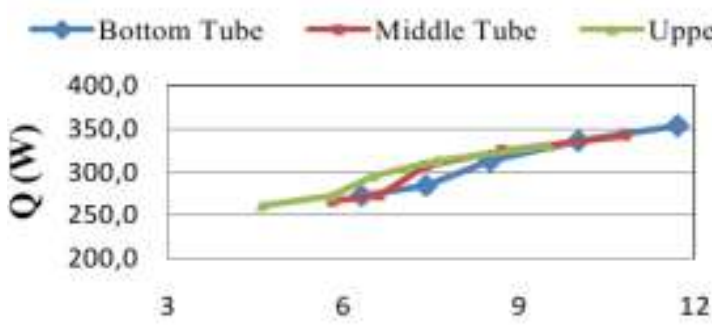

$\Delta T(k)$

Figure 4.2.1 Heat Transfer Rates for $0^{\circ}$ of Inclination of

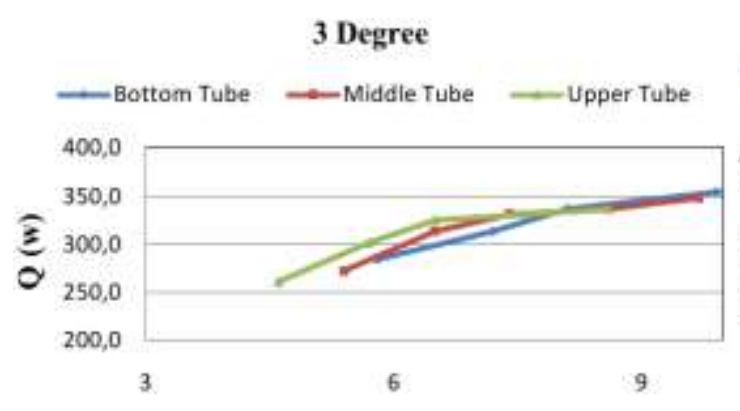

$\Delta \mathrm{T}(\mathrm{k})$

Figure 4.2.3 Heat Transfer Rates for $3^{\circ}$ of Inclination of Inclination

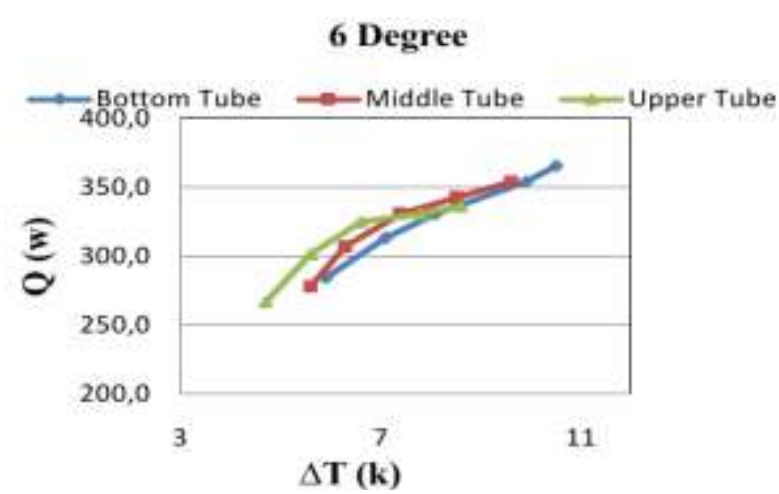

Figure 4.2.5 Heat Transfer Rates for $6^{\circ}$ of Inclination Inclination
0 Degree

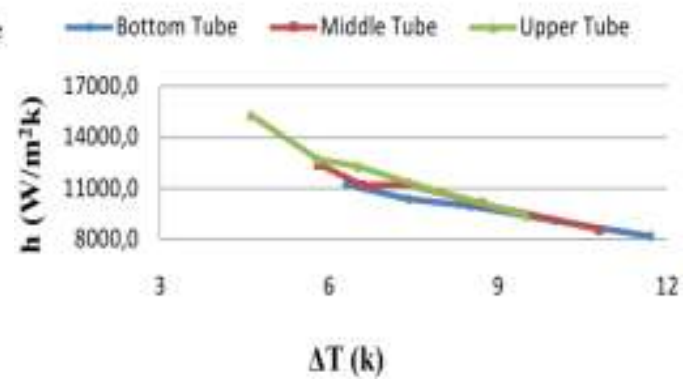

Figure 4.2.2 Heat Transfer Coefficients for $0^{\circ}$ Inclination

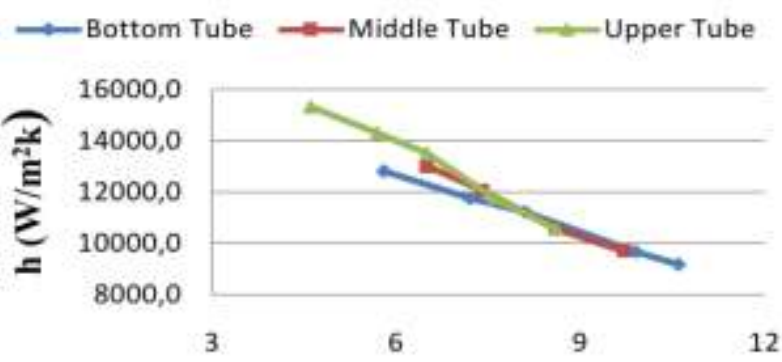

$\Delta \mathrm{T}(\mathrm{k})$

Figure 4.2.4 Heat Transfer Coefficients for $3^{\circ}$

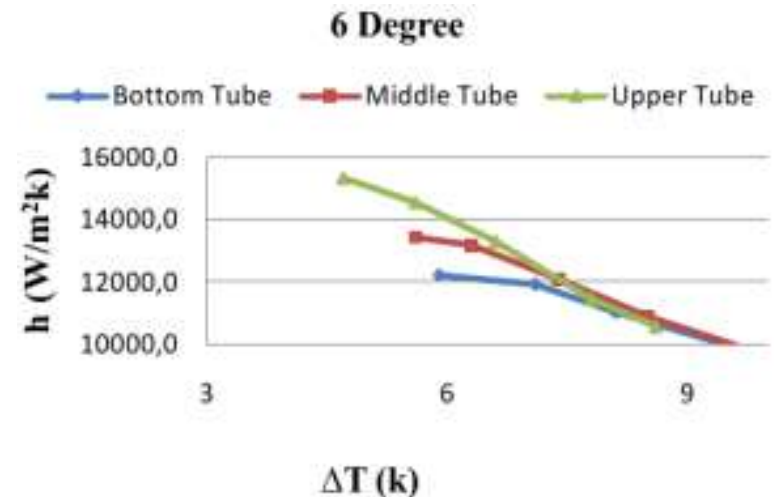

Figure 4.2.6 Heat Transfer Coefficients for $6^{\circ}$ of 
10 Degree

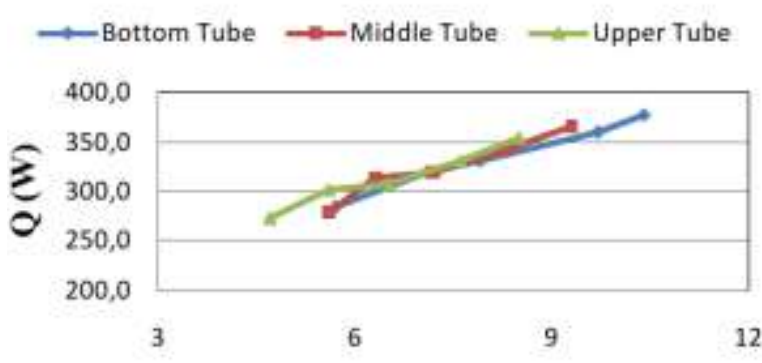

$\Delta \mathrm{T}(\mathrm{k})$

Figure 4.2.7 Heat Transfer Rates for $10^{\circ}$ of Inclination $10^{\circ}$ of Inclination

\section{Degree}

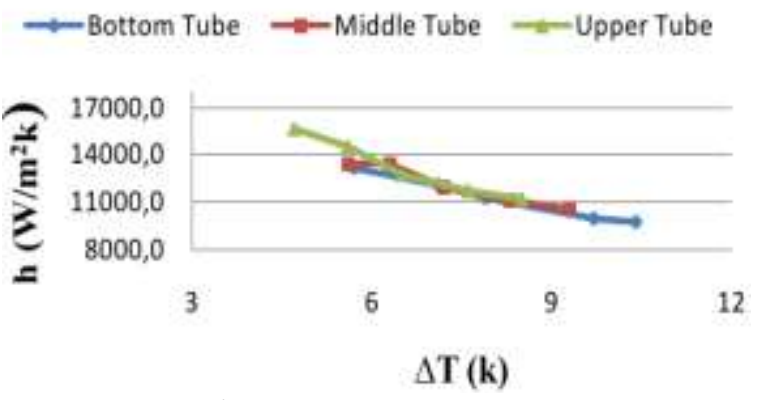

Figure 4.2.8 Heat Transfer Coefficients for

\section{Degree}

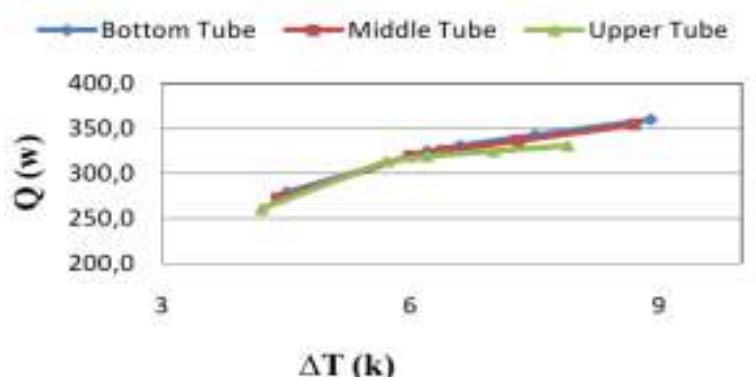

Figure 4.2.9 Heat Transfer Rates for $15^{\circ}$ of Inclination of Inclination

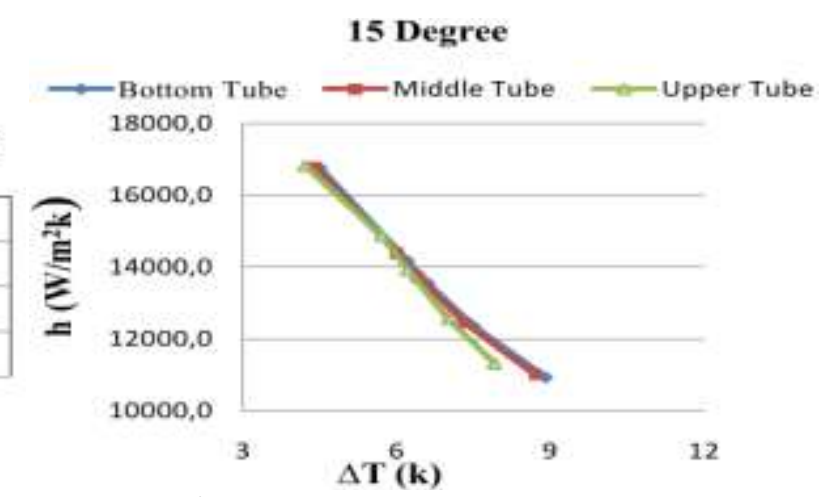

Figure 4.2.10 Heat Transfer Coefficients for $15^{\circ}$

\subsection{Uncertainty Analysis}

There are two methods to calculated uncertainties; the worst-case combination and constant odds combination. According to the constant odds method, if a result $r$ is to be calculated by a function $r=r(x 1, x 2 \ldots X$ $\mathrm{n}$ ) input data $\mathrm{x}_{\mathrm{i}}$, then the uncertainty in $\mathrm{r}$ is given by

$w_{R}=\left[\left(\frac{\partial R}{\partial x_{1}} w_{1}\right)^{2}+\left(\frac{\partial R}{\partial x_{2}} w_{2}\right)^{2}+\cdots+\left(\frac{\partial R}{\partial x_{n}} w_{n}\right)^{2}\right]^{\frac{1}{2}}$

As kline and mcclintock claimed [7] equation a gives the uncertainty in $r$ with good accuracy for most functions of engineering importance, and therefore will be employed to calculate the uncertainties in these studies. Yamal1, c [8] the rate of heat transfer and the heat transfer coefficient of the experiments are calculated with equations4.1 \& 4.2. Yamalı the uncertainties in the calculations of the equations will be determined for the results of the experiments which were conducted at vertical position. The values of the variables used in the equations and the uncertainties related to these variables are presented in table A.

Table A uncertainties of the independent variables used in equation 4.1 and 4.2

\begin{tabular}{|l|l|l|l|}
\hline Variable & Upper Tube & Middle Tube & Bottom Tube \\
\hline $\mathrm{m}(\mathrm{g} / \mathrm{s})$ & $13.89 \pm 0.1$ & $13.89 \pm 0.1$ & $13.89 \pm 0.1$ \\
\hline $\mathrm{C}_{\mathrm{p}}(\mathrm{j} \mathrm{kg} \mathrm{k})$ & $4181 \pm 1$ & $4181 \pm 1$ & $4181 \pm 1$ \\
\hline $\mathrm{T}_{\text {in }}\left({ }^{\circ} \mathrm{C}\right)$ & $17.2 \pm 0.1$ & $17.1 \pm 0.1$ & $17.2 \pm 0.1$ \\
\hline $\mathrm{T}_{\text {out }}\left({ }^{\circ} \mathrm{C}\right)$ & $23.3 \pm 0.1$ & $23.3 \pm 0.1$ & $22.9 \pm 0.1$ \\
\hline $\mathrm{r}(\mathrm{mm})$ & $9.5 \pm 0.01$ & $9.5 \pm 0.01$ & $9.5 \pm 0.01$ \\
\hline $\mathrm{L}(\mathrm{mm})$ & $62 \pm 1$ & $62 \pm 1$ & $62 \pm 1$ \\
\hline $\mathrm{T}_{\text {sat }}\left({ }^{\circ} \mathrm{C}\right)$ & $97.9 \pm 0.1$ & $97.9 \pm 0.1$ & $97.9 \pm 0.1$ \\
\hline $\mathrm{T}_{\mathrm{w}}\left({ }^{\circ} \mathrm{C}\right)$ & $89.1 \pm 0.1$ & $89.1 \pm 0.1$ & $86.8 \pm 0.1$ \\
\hline
\end{tabular}

A sample calculation of uncertainty in equation 4.1 for the upper tube is presented in the following. 
$Q=\dot{m} C_{p}\left(T_{\text {out }}-T_{\text {in }}\right)=348.45$

$\frac{\partial Q}{\partial \dot{m}}=C_{p}\left(T_{\text {out }}-T_{\text {in }}\right)$

$\frac{\partial Q}{\partial C_{p}}=\dot{m}\left(T_{\text {out }}-T_{\text {in }}\right)$

$\frac{\partial Q}{\partial T_{\text {in }}}=-\dot{m} C_{p}$

$\frac{\partial Q}{\partial T_{\text {out }}}=\dot{m} C_{p}$

$w_{\dot{m}}= \pm 0.1$

$w_{C_{p}}= \pm 1$

$w_{T_{\text {in }}}= \pm 0.1$

$w_{T_{\text {out }}}= \pm 0.1$

Substituting these values into equation $\mathrm{A}$

$w_{Q}=\left[\left(\frac{\partial Q}{\partial \dot{m}} w_{\dot{m}}\right)^{2}+\left(\frac{\partial Q}{\partial C_{p}} w_{C_{p}}\right)^{2}+\left(\frac{\partial Q}{\partial T_{\text {in }}} w_{T_{\text {in }}}\right)^{2}+\left(\frac{\partial Q}{\partial T_{\text {out }}} w_{T_{\text {out }}}\right)^{2}\right]^{\frac{1}{2}}$

$w_{Q}=8.59$

Uncertainty $(\%)=\frac{w_{Q}}{Q}=2.48$

Table B uncertainties in the experimental results

\begin{tabular}{|c|c|c|}
\hline $\mathbf{0}^{\circ}$ Inclination & Uncertainty in Q (\%) & Uncertainty in h (\%) \\
\hline Upper Tube & $2.48 \%$ & 2.21 \\
\hline Middle Tube & $2.50 \%$ & 2.10 \\
\hline Bottom Tube & $2.58 \%$ & 2.01 \\
\hline
\end{tabular}

\subsection{Comparison of Experimental Results with Analytical Results}

The heat transfer coefficients of each condensation tubes which were obtained from the experiments conducted at the vertical position and the analytical investigation are presented in Figures 4.4.1. Even though the heat transfer coefficients obtained by the analytical method agree with the Nusselt's analysis, they are less than those of the experimental results.

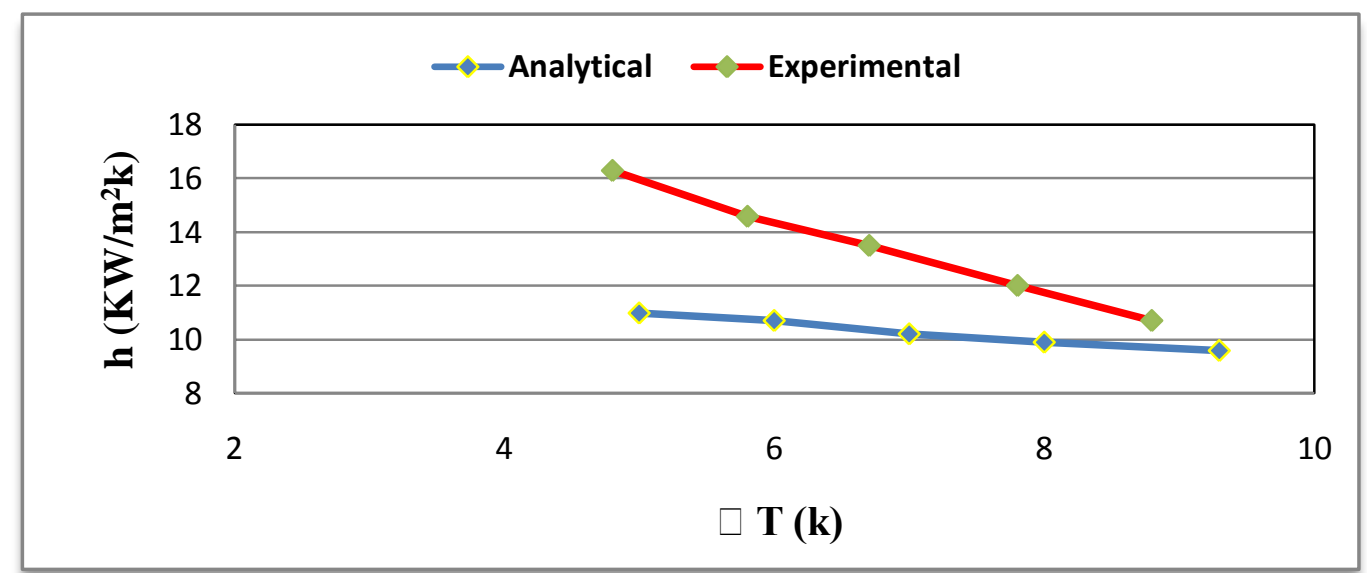

Figure 4.4.1 Comparisons of Heat Transfer Coefficients Between Analytical and Experimental Analyses .

\section{Conclusion}

Experimental data are presented for condensation of steam on a vertical tier of three condensation tubes the conclusions drawn from the present study are as follows:

It is concluded from the experiments of the first stage that the heat transfer rate is slightly increased at the middle and the bottom tubes by inclining the test section, and no significant change in the heat transfer coefficient of the upper tube is observed.

It is concluded from the experiments of the second stage that the rate of heat transfer is significantly increased due 
to the sweep effect of steam on the condensate.

However, it is seen from the third stage experiments that the distance between the condensation tubes does not have a considerable effect on condensation.

Finally this is concluded that the steam condensation on vertical tier of horizontal tube has considered the effect of following factors:

- Diameter of horizontal tube

- Temperature difference between the steam \& tube wall

- Angle of inclination of tube

- Condensation surface

Comparison of the experimental results with the literature show that although the heat transfers coefficients found by the present study are less than those found by some researchers, they are greater than those predicted by Nusselt's analysis.

\section{References}

[1] Nusselt, W., Die Oberflachen-Kondensation des Wasserdampfes, Zeitschrift des Vereines deutscher Ingenieure, 60, 541-546, 569-575, 1916.

[2] Dukler, a. E., fluid mechanics and heat transfer in vertical falling-film systems, chemical engineering progress symposium series no.30, 56, 1-10, 1960 .

[3] Abdullah,r.,cooper,j.R.,Briggs,a.,rose,j.W condensation of steam and r113 on a bank of horizontal tubes in the presence of a non condensing gas, experimental thermal and fluid science, 10, 298-306, 1995.

[4] Kumar, r., Varma, h. K., Mohanty ,b., Agrawal, k. N., augmentation of outside tube heat transfer coefficient during condensation of steam over horizontal copper tubes, international communications in heat and mass transfer, 25, 81-91, 1998.

[5] Kutateladze,s.s.,gogonin,i.i.,sosunov,v.i.,theinfluenceofcondensate flow rate on heat transfer in film condensation of stationary vapor on horizontal tube banks, internationaljournalofheatandmasstransfer,28,1011-1018, 1985.

[6] Kutateladze, S. S. and Gogonin, I. I., Heat transfer in condensation of flowing vapor on a single horizontal cylinder, International Journal of Heat and Mass Transfer, 28, 1019-1030, 1985.

[7] Chen, M. M., an analytical study of laminar film condensation: part 2- single and multiple horizontal tubes, journal of heat transfer, $83 c, 55-60,1961$.

[8] Kline, S.J. and Mcclintock, F.A., describing uncertainties in single sample experiments, mechanical engineering, Jan. 1953.

[9] Yamall, C., drop wise condensation under high gravity and at large sub cooling, Ph.D. Dissertation, university of Michigan, 1983

[10] Sparrow, E. M. and Gregg, J. L., Laminar condensation heat transfers on a Horizontal cylinder, Journal of Heat Transfer, 81C, 291295 , and 1959.

[11] Denny, V. E. and Mills, A. F., Laminar film condensation of a flowing vapor On a horizontal cylinder at normal gravity, Journal of Heat Transfer, 495-501, 1969.

[12] Kakaç, S. and Liu, H., Heat exchangers: selection, rating, and thermal design, CRC Press, Boca Raton, Fla, 1998 